$\stackrel{N / N}{=}$

Global journals Inc.

है

\title{
Essential Medicine and Equipment for Emergency Obstetric and Newborn Care in Zanzibar: Situation at a Glance
}

\author{
By Andrea B. Pembe, Bruno Sunguya, Stella Mushy, Sebalda Leshabari, \\ George Kiwango, Chirsker Masaki \& Linda B. Mlunde \\ Muhimbili University of Health and Allied Sciences
}

Abstract- Background: Maternal and neonatal mortality are unacceptably high in Zanzibar. Maternal mortality and neonatal mortality ratio stand at 350 per 100,000 live births and 29 per 1,000 live births respectively as of 2018. Addressing challenges facing maternal and newborn health requires among others, the assurance of essential medicine and equipment to deliver evidence based interventions. This paper reports evidence gathered on the availability of essential medicines and equipment in providing Emergency Obstetric and Newborn Care (EmoNC) services in Zanzibar.

Methods: A cross-sectional mixed methods study design was used to collect information on the availability of drugs and equipment from all health facilities providing delivery services in Zanzibar. Semi-structure interview guide was used to carry in-depth interviews (IDIs) with health facility in-charges while observation on availability of essential medicine and equipment for EmONC was carried using standard observation guide as adopted from Averting Maternal Death and Disability program.

Keywords: emergency obstetric and new-born care, maternal health, signal functions, essential medicine, zanzibar, drugs and supplies, tanzania.

GJMR-K Classification: NLMC Code: WS 205

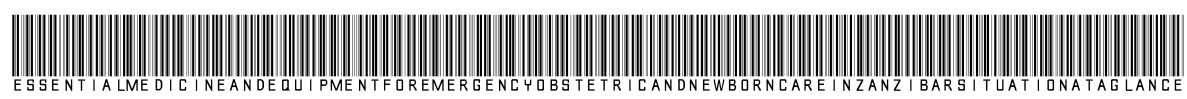

Strictly as per the compliance and regulations of:

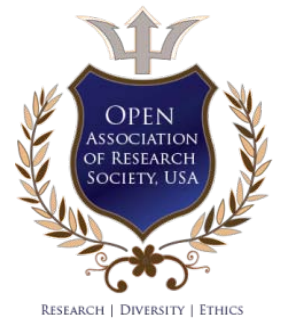

(C) 2019. Andrea B. Pembe, Bruno Sunguya, Stella Mushy, Sebalda Leshabari, George Kiwango, Chirsker Masaki \& Linda B. Mlunde. This is a research/review paper, distributed under the terms of the Creative Commons Attribution-Noncommercial 3.0 Unported License http://creativecommons.org/licenses/by-nc/3.0/), permitting all non commercial use, distribution, and reproduction inany medium, provided the original work is properly cited. 


\title{
Essential Medicine and Equipment for Emergency Obstetric and Newborn Care in Zanzibar: Situation at a Glance
}

\author{
Andrea B. Pembe ${ }^{\alpha}$, Bruno Sunguya ${ }^{\circ}$, Stella Mushy ${ }^{\circ}$, Sebalda Leshabari ${ }^{\omega}$, George Kiwango ${ }^{*}$, \\ Chirsker Masaki $^{\S} \&$ Linda B. Mlunde ${ }^{x}$
}

\begin{abstract}
Background: Maternal and neonatal mortality are unacceptably high in Zanzibar. Maternal mortality and neonatal mortality ratio stand at 350 per 100,000 live births and 29 per 1,000 live births respectively as of 2018 . Addressing challenges facing maternal and newborn health requires among others, the assurance of essential medicine and equipment to deliver evidence based interventions. This paper reports evidence gathered on the availability of essential medicines and equipment in providing Emergency Obstetric and Newborn Care (EmoNC) services in Zanzibar.

Methods: A cross-sectional mixed methods study design was used to collect information on the availability of drugs and equipment from all health facilities providing delivery services in Zanzibar. Semi-structure interview guide was used to carry in-depth interviews (IDIs) with health facility in-charges while observation on availability of essential medicine and equipment for EmONC was carried using standard observation guide as adopted from Averting Maternal Death and Disability program. Thematic analysis was adopted for the IDls, and a descriptive analysis was carried out for the observation data with the aid of STATA computer programme and results were summarized in frequency tables and figures.
\end{abstract}

Results: Evidence shows that there is still a challenge in the availability of essential medicine and supplies in health facilities. The most common available antibiotic was amoxicillin, available in $\mathbf{8 6 . 3 \%}$ of all health facilities. In almost all essential medicines, availability is lower in lower levels health facilities compared to higher levels. For example, diazepam was available in $85.7 \%$ of hospitals but only in $55 \%$ of lower level health facilities. Majority of the delivery health facilities had items for the delivery set. The least found items in the delivery set were long gloves and pean artery forceps which were found in only $13.7 \%$ and $37.3 \%$ of all the facilities respectively. The shortage of equipment affected lower level facilities more than higher level facilities. For instance, episiotomy scissors were found in $71.4 \%$ of higher level but in $57.5 \%$ of lower health facilities.

Conclusion: Delivery of quality EmONC in Zanzibar is challenged by inadequate availability of medicines and equipment in facilities especially the $\mathrm{PHCU}+$ and $\mathrm{PHCC}$. None

Author $\alpha ¥$ : School of Medicine, Muhimbili University of Health and Allied Sciences, Dar es salaam, Tanzania.

e-mail: andreapembe@yahoo.co.uk

Author $\rho$ w: School of Nursing, Muhimbili University of Health and Allied Sciences, Dar es salaam, Tanzania.

Author o: School of Public Health and Social Sciences, Muhimbili University of Health and Allied Sciences, Dar es salaam, Tanzania.

Author \&: Eastern Africa Statistical Training Centre, Dar es Salaam.

Author $\chi$ : Implementation Science Tanzania, Dar es salaam, Tanzania. of the PHCU+ has all the essential drugs and equipment to deliver EmONC thus exposing the women and newborns to morbidity and mortality. To ensure delivery of quality EmONC, it is important to ensure adequate availability of all essential antibiotics, antihypertensives, anticonvulsants, and equipment for delivery, removal of products of conception and resuscitation of newborns in Zanzibar.

Keywords: emergency obstetric and new-born care, maternal health, signal functions, essential medicine, zanzibar, drugs and supplies, tanzania.

Keywords: EmONC, essential medicine, resuscitation, maternal health, Zanzibar.

\section{BACKGROUND}

A Ithough, the global maternal deaths dropped from 532,000 in the 1990s to 303,000 in 2015 (1), the burden has remained unacceptably high. Furthermore, estimates show that 99\% of all maternal deaths occur in low- and middle-income countries with $66 \%$ of maternal deaths occurring in sub-Saharan Africa (1).

Improvement of maternal health indicators calls for health system strengthening. One of the six important health system pillars is ensuring availability of medicine and supplies. For maternal health, lack or challenge in such important pillar is behind a number of preventable maternal deaths globally, and Tanzania is not an exception. Availability and provision of essential medicines including parenteral antibiotics, uterotonic drugs, parenteral anticonvulsants and anaesthetic drugs; and equipment including manual vacuum aspirators, vacuum extractor and set for basic neonatal resuscitation are therefore vital in addressing the direct causes of maternal and newborn deaths. Major direct causes of maternal deaths including infections, hypertensive disease in pregnancy and eclampsia, bleeding, obstructed labor, abortion complications $(2,3)$ and causes of newborn deaths can be averted by providing Emergency Obstetric and Neonatal care (EmONC) (4).

Tanzania (comprised of mainland and Zanzibar islands) like other sub-Saharan Africa has a high maternal mortality ratio of 556 deaths per 100,000 live births (5) with a significant variation between regions and geographical areas. Zanzibar records maternal 
mortality ratio as high as 350/100,000 live births (6). While Zanzibar has made significant gains in reducing infant mortality from 54 deaths per 1000 live births in 2010 to 45 deaths per 1000 live births in 2015. Facilitybased data show an increase of maternal deaths from 187 per 100,000 live births in 2014 to 276 maternal deaths per 100,000 live births in 2016. For the neonatal mortality, another important indicator, is still very high at a level of 25 neonatal deaths per 1000 live births (5).

While poor access to health facilities contribute to high burdens of maternal and neonatal mortality in many parts of the world (7), women in Zanzibar may have a different set of challenges as $95 \%$ of the population live close proximity to health facilities and have access to care (2). Evidence gathered from Zanzibar revealed shortage of drugs and supplies contribute to this poor trend in maternal mortality. The ministry of health and implementing UNFPA commissioned a survey in 2012 to assess Emergency Obstetric and Neonatal Care (EmONC) indicators in the isles that show similar challenges reported. However, how much has been done with respect to providing the facilities with equipment and medical supplies since those studies were conducted remains unknown. This is a follow up survey aimed to examine the changes made in this regard. It aimed at documenting the situation at glance with respect to essential medicines and equipment for provision of quality EmONC in Zanzibar.

\section{Methods}

\section{a) Study design}

A cross sectional mixed methods study design employing both quantitative and qualitative approaches was used. The quantitative approach used systematic observation while the qualitative approach adopted indepth interviews with key stakeholders on availability of medicine for provision of maternal and newborn care.

\section{b) Study setting}

This study was part of the larger study to assess EmONC in Zanzibar in the year 2018. The health care system is organized into three levels, the primary, secondary, and tertiary levels. More details on the study setting and sampling are provided elsewhere (8). The focus of this study is on the 51 facilities offering delivery services including the National, Mnazi Mmoja hospital; five district hospitals and one maternity hospital; four primary health care centers (PHCC); 33 primary health care unit plus $(\mathrm{PHCU}+)$ and seven primary health care units (PHCU).

\section{c) Data collection}

Data collection was done using the Averting Maternal Death and Disability (AMDD) (9) program tools to observe the availability of medicines and equipment and medical supplies for EmONC. The tools were formatted to suit Open Data Kit (ODK) format and uploaded to tablets that were used for data collection.

For the qualitative part, a semi-structured interview guide was used to interview the in-charge or a health worker who provides maternal and new born services in the respective health facility. The later was developed based on prior knowledge of the investigators and literature existed on the question under study. The interviews were scheduled to fit the convenience of the informant and they were carried out in privacy within the facility. Experienced qualitative researchers who were accompanied by trained research assistants for notes taking and audio recording carried out the interviews in Swahili, using digital voice recorders.

\section{d) Data analysis}

Quantitative data were transformed from the ODK server to STATA for analysis. Descriptive analyses were conducted and results summarized in frequency tables and figures. The health facilities were grouped into 4, hospitals including the National hospital, district hospitals and maternity hospital, PHCC and $\mathrm{PHCU}+/ \mathrm{PHCU}$. For the qualitative data analysis, first, we transcribed verbatim all audio-recorded interviews. In order to become familiar with the content and context, all authors read the full transcripts and field notes repeatedly before the start of analysis. We used a hybrid thematic data analysis approach; this approach used both inductive and deductive reasoning.

\section{e) Ethical consideration}

The study was approved by the Zanzibar Medical Research Ethics Council (ZAMREC) and the permission to conduct the study was given by the Ministry of Health of the Revolutionary Government and respective regions, districts and facility authorities. Participation into the study was voluntary, and researchers ensured confidentiality and privacy of participants. Participants signed an informed consent before interviews and were free to stop the interview at any time without repercussion.

\section{Results}

\section{a) Availability of essential drugs}

Levels of availability of essential medicine varied widely (Table 1). The most common available antibiotic was amoxicillin, available in $86.3 \%$ of all health facilities. The least available were cephazoline sodium, chloramphenicol (injection), clindamycin, and cloxacillin sodium all in $3.9 \%$ of all health facilities respectively. In almost all essential medicines, availability is lower in lower levels health facilities compared to PHCC and above levels.

For anticonvulsants, magnesium sulphate was available in only $76.5 \%$ of facilities providing delivery services. Only two thirds of facilities had diazepam while 
phenobabrbitone was available in only one quarter. In this regard too, availability levels were lower in lower levels health facilities compared to those in PHCC and above. For antihypertensives, Nifedipine was available in three quarter of the health facilities. However, other essential antihypertensive medicines such as methyl- dopa and hydralazine were available in only $27.5 \%$ and $21.6 \%$ respectively. Oxytocin was available in $92.2 \%$ of the facilities, however one fourth of facilities did not have misoprostol and ergometrine was rarely available. The trend was almost the same for all levels of facilities.

Table 1: Availability of drugs in the health facilities on the day of the visit

\begin{tabular}{|l|c|c|c|c|}
\hline \multicolumn{1}{|c|}{ Drugs } & & \multicolumn{3}{c|}{ Health facility level } \\
\hline & Total & Hospitals & PHCC & PHCU+/PHCU \\
& $\mathrm{N}=51$ & $\mathrm{~N}=7$ & $\mathbf{N}=4$ & 40 \\
\hline & $\mathrm{n}(\%)$ & $\mathrm{n}(\%)$ & $\mathrm{n}(\%)$ & $\mathrm{n}(\%)$ \\
\hline Antibiotics & & & & \\
\hline Amoxicillin & $44(86.3)$ & $7(100.0)$ & $4(100.0)$ & $33(82.5)$ \\
\hline Ampicillin & $10(19.6)$ & $2(28.6)$ & $1(2.0)$ & $7(17.5)$ \\
\hline Cephazoline sodium & $2(3.9)$ & $0(0.0)$ & $0(0.0)$ & $2(5.0)$ \\
\hline Cefixime & $6(11.8)$ & $3(42.9)$ & $1(25.0)$ & $2(5.0)$ \\
\hline Ceftriaxone & $34(6.7)$ & $6(85.7)$ & $4(100.0)$ & $24(60.0)$ \\
\hline Chloramphenicol (injection) & $2(3.9)$ & $1(14.3)$ & $0(0.0)$ & $1(2.5)$ \\
\hline Clindamycin & $2(3.9)$ & $1(14.3)$ & $0(0.0)$ & $1(2.5)$ \\
\hline Cloxacillin sodium & $2(3.9)$ & $0(0.0)$ & $0(0.0)$ & $2(5.0)$ \\
\hline Gentamycin & $15(29.4)$ & $7(100.0)$ & $1(25.0)$ & $7(17.5)$ \\
\hline Metronidazole injection & $20(39.2)$ & $7(100.0)$ & $4(100.0)$ & $9(22.5)$ \\
\hline Benzyl penicillin & $17(33.3)$ & $5(71.4)$ & $2(50.0)$ & $10(25.0)$ \\
\hline Procaine Benzylpenicillin & $19(37.3)$ & $5(71.4)$ & $1(25.0)$ & $13(32.5)$ \\
\hline Anticonvulsants & & & & \\
\hline Magnesium sulphate (injection) & $39(76.5)$ & $7(100.0)$ & $4(100.0)$ & $28(70.0)$ \\
\hline Diazepam & $31(60.8)$ & $6(85.7)$ & $3(75.0)$ & $22(55.0)$ \\
\hline Phenobarbitone & $11(21.6)$ & $3(42.9)$ & $1(25.0)$ & $7(17.5)$ \\
\hline Phenyton & $4(7.8)$ & $2(28.6)$ & $0(0.0)$ & $2(5.0)$ \\
\hline Antihypertensives & & & & \\
\hline Hydralazine & $11(21.6)$ & $7(100.0)$ & $2(50.0)$ & $2(5.0)$ \\
\hline Labetalol & $1(2.0)$ & $1(14.3)$ & $0(0.0)$ & $0(0.0)$ \\
\hline Methyldopa & $14(27.5)$ & $7(100.0)$ & $1(25.0)$ & $6(15.0)$ \\
\hline Nifedipine & $39(76.5)$ & $6(85.7)$ & $4(100.0)$ & $29(72.5)$ \\
\hline Oxytocics & & & & \\
\hline Oxytocin & $47(92.2)$ & $7(100.0)$ & $4(100.0)$ & $36(90.0)$ \\
\hline Ergometrine & $2(3.9)$ & $1(14.3)$ & $0(0.0)$ & $1(2.5)$ \\
\hline Misoprostol & $35(68.6)$ & $7(100.0)$ & $4(100.0)$ & $24(60.0)$ \\
\hline
\end{tabular}

b) Stock out of drugs within the past three and six months

To get the insight of the real situation we also collected data on the drugs stock out within the past three and six months. The essential antibiotics assessed included ampicillin, gentamicin injection, metronidazole injection, penicillin $\mathrm{G}$, and procaine benzylpenicillin. Table 2 shows that, a total of 34 health facilities confirmed they had stock out of any of the mentioned essential antibiotic. This is $67 \%$ of all facilities and the challenge is higher in lower level facilities compared to higher ones. More than two thirds of PHCU had such stock out. In terms of duration, the analyses suggest that $12 \%$ of facilities had shortage in the past three months and all of them in lower level facilities. Compared to antibiotics, there was no significant challenge in stock out of oxytocics. Only three out of 51 facilities reported stock out of oxytocics. All of them are the low-level health facilities. Looking into three- or six-months records, only one facility had such shortage.

Table 2: Stock out of drugs in the health facilities providing delivery services in the past 3 and 6 months

\begin{tabular}{|l|c|c|c|c|}
\hline \multicolumn{1}{|c|}{ Drugs } & \multicolumn{3}{c|}{ Health facility level } \\
\hline & $\begin{array}{c}\text { Total } \\
\mathrm{N}=51\end{array}$ & $\begin{array}{c}\text { Hospitals } \\
\mathrm{N}=7\end{array}$ & $\begin{array}{c}\mathrm{PHCC} \\
\mathrm{N}=4\end{array}$ & $\begin{array}{c}\text { PHCU+/PHCU } \\
\mathrm{N}=40\end{array}$ \\
\hline & $\mathrm{n}(\%)$ & $\mathrm{n}(\%)$ & $\mathrm{n}(\%)$ & $\mathrm{n}(\%)$ \\
\hline Any antibiotics stock out & & & & \\
\hline Yes & $34(66.7)$ & $2(28.6)$ & $2(50.0)$ & $30(75.0)$ \\
\hline No & $15(29.4)$ & $5(71.4)$ & $2(50.0)$ & $8(20.0)$ \\
\hline
\end{tabular}




\begin{tabular}{|l|c|c|c|c|}
\hline Facility had never had these medicines & $2(3.9)$ & $0(0.0)$ & $0(0.0)$ & $2(5.0)$ \\
\hline Any antibiotics stock out & & & & \\
\hline Past three months & $6(11.7)$ & $0(0.0)$ & $0(0.0)$ & $6(15.0)$ \\
\hline Past six months & $1(2.0)$ & $0(0.0)$ & $0(0.0)$ & $1(2.5)$ \\
\hline Oxytocics stock out & & & & \\
\hline Yes & $3(5.9)$ & $0(0.0)$ & $0(0.0)$ & $3(7.5)$ \\
\hline No & $48(94.1)$ & $7(100.0)$ & $4(100.0)$ & $37(92.5)$ \\
\hline Oxytocics stock out & & & & \\
\hline Past three months & $1(2.0)$ & $0(0.0)$ & $0(0.0)$ & $1(2.0)$ \\
\hline Past six months & $1(2.0)$ & $0(0.0)$ & $0(0.0)$ & $1(2.0)$ \\
\hline
\end{tabular}

From the interviews, majority of the participants (public and private facilities) reported that the frequency of drugs stock out has declined as compared to previous years.

"About drugs we thank God because the most used drugs here like hydralazine, methyldopa, and antibiotics are available most of the time (General Nurse-1).

In other facilities despite acknowledging the declining in stock out frequency in general, participants stated that there was still frequently stock outs for some specific drugs.
"Most of the drugs we mainly use in maternity are available, but for the last two months (March and April) we have been getting inadequate ferrous sulphate drugs" (General nurse-2).

\section{c) Availability of equipment}

Majority of the delivery health facilities had items included in the delivery set. The least found items in the delivery set were long gloves, and pean artery forceps which were found in only $13.7 \%$ and $37.3 \%$ of all the facilities. The shortage of equipment affected lower level facilities more than higher level facilities (Table 3).

Table 3: Availability of delivery set/pack in health facilities providing delivery services $(\mathrm{N}=51)$

\begin{tabular}{|l|c|c|c|c|}
\hline \multicolumn{1}{|c|}{ Equipment and supplies } & \multicolumn{3}{|c|}{ Health facility level } \\
\hline & $\begin{array}{c}\text { Total } \\
(\mathbf{N}=51)\end{array}$ & $\begin{array}{c}\text { Hospitals } \\
(\mathbf{N}=7)\end{array}$ & $\begin{array}{c}\text { PHCC } \\
(\mathbf{N}=4)\end{array}$ & $\begin{array}{c}\text { PHCU+/PHCU } \\
(\mathbf{N}=40)\end{array}$ \\
\hline & $\mathrm{n}(\%)$ & $\mathbf{n}(\%)$ & $\mathrm{n}(\%)$ & $\mathrm{n}(\%)$ \\
\hline Artery forceps, 18cm, CVD & $33(64.7)$ & $3(42.9)$ & $3(75.0)$ & $27(67.5)$ \\
\hline Sponge (ring) forceps & $36(70.6)$ & $7(100.0)$ & $3(75.0)$ & $26(65.0)$ \\
\hline Dissecting forceps, standard pattern & $32(67.4)$ & $5(71.4)$ & $3(75.0)$ & $24(60.0)$ \\
\hline Pean artery forceps, straight & $19(37.3)$ & $4(57.1)$ & $1(25.0)$ & $14(35.0)$ \\
\hline Cord-cutting scissors, curved, & $41(80.4)$ & $6(85.7)$ & $3(75.0)$ & $32(80.0)$ \\
\hline Cord ties & $36(70.6)$ & $5(71.4)$ & $2(50.0)$ & $29(72.5)$ \\
\hline Episiotomy scissors, angular & $31(60.8)$ & $5(71.4)$ & $3(75.0)$ & $23(57.5)$ \\
\hline Straight stitch scissors & $23(45.1)$ & $4(57.1)$ & $3(75.0)$ & $16(40.0)$ \\
\hline Gloves & $45(88.2)$ & $7(100.0)$ & $4(100.0)$ & $34(85.0)$ \\
\hline Long gloves & $7(13.7)$ & $4(57.1)$ & $0(0.0)$ & $3(7.5)$ \\
\hline Plastic sheeting & $30(58.8)$ & $5(71.4)$ & $3(75.0)$ & $22(55.0)$ \\
\hline Gauze swabs & $47(92.2)$ & $7(100.0)$ & $4(100.0)$ & $36(90.0)$ \\
\hline Clothes & $14(27.5)$ & $4(57.1)$ & $2(50.0)$ & $8(20.0)$ \\
\hline
\end{tabular}

Table 4 shows the results of availability of manual vacuum aspiration equipment in health facility providing delivery services. Of all the facilities, less than half had the equipment. It is worth-noting that, lower level health facilities bears the bigger brunt of such deficiency.

Table 4: Availability of manual vacuum aspiration equipment in health facilities providing delivery services $(\mathrm{N}=51)$

\begin{tabular}{|l|c|c|c|c|}
\hline \multicolumn{1}{|c|}{ Equipment and supplies } & \multicolumn{3}{|c|}{ Health facility level } \\
\hline & $\begin{array}{c}\text { Total } \\
(\mathrm{N}=51)\end{array}$ & $\begin{array}{c}\text { Hospitals } \\
(\mathbf{N}=7)\end{array}$ & $\begin{array}{c}\text { PHCC } \\
(\mathrm{N}=4)\end{array}$ & $\begin{array}{c}\text { PHCU+/PHCU } \\
(\mathrm{N}=40)\end{array}$ \\
\hline & $\mathrm{n}(\%)$ & $\mathrm{n}(\%)$ & $\mathrm{n}(\%)$ & $\mathrm{n}(\%)$ \\
\hline Vacuum aspirators/syringes & $22(43.1)$ & $4(57.1)$ & $4(100.0)$ & $14(35.0)$ \\
\hline Silicone lubricant & $9(17.7)$ & $2(28.6)$ & $1(25.0)$ & $6(15.0)$ \\
\hline Other lubricant oil & $6(11.8)$ & $2(28.6)$ & $3(75.0)$ & $1(2.5)$ \\
\hline Flexible cannulae (all sizes) & $13(25.5)$ & $3(42.9)$ & $2(50.0)$ & $8(20.0)$ \\
\hline
\end{tabular}

Table 5 shows the neonatal resuscitation pack items found in delivery health facilities. The commonest items found are ambu bag (90.2\%) and infant face masks (80.4). The least items found in the facilities are
Infant laryngoscope with spare bulb and batteries and endotracheal tubes both found at $9.8 \%$ of all the delivery health facilities. A low proportion of the low-level health facilities had the resuscitation pack items. 
Table 5: Availability of neonatal resuscitation pack in health facilities providing delivery services $(\mathrm{N}=51)$

\begin{tabular}{|l|c|c|c|c|}
\hline \multicolumn{1}{|c|}{ Equipment and supplies } & \multicolumn{3}{c|}{ Health facility level } \\
\hline & $\begin{array}{c}\text { Total } \\
(\mathrm{N}=51)\end{array}$ & $\begin{array}{c}\text { Hospitals } \\
(\mathrm{N}=7)\end{array}$ & $\begin{array}{c}\text { PHCC } \\
(\mathrm{N}=4)\end{array}$ & $\begin{array}{c}\text { PHCU+/PHCU } \\
(\mathrm{N}=40)\end{array}$ \\
\hline & $\mathrm{n}(\%)$ & $\mathrm{n}(\%)$ & $\mathrm{n}(\%)$ & $\mathrm{n}(\%)$ \\
\hline Mucus extractor & $27(52.9)$ & $3(42.9)$ & $3(75.0)$ & $21(52.5)$ \\
\hline Infant face masks, sizes 0,1,2 & $41(80.4)$ & $7(100.0)$ & $4(100.0)$ & $30(75.0)$ \\
\hline Ambu (ventilator) bag & $46(90.2)$ & $7(100.0)$ & $4(100.0)$ & $35(87.5)$ \\
\hline Suction catheter, 10, 12 Ch & $28(54.9)$ & $6(85.7)$ & $4(100.0)$ & $18(45.0)$ \\
\hline Infant laryngoscope with spare bulb and batteries & $5(9.8)$ & $2(28.6)$ & $1(25.0)$ & $2(5.0)$ \\
\hline Endotracheal tubes, 3.5, 3.0 & $5(9.8)$ & $2(28.6)$ & $1(25.0)$ & $2(5.0)$ \\
\hline Disposable uncuffed tracheal tubes, sizes 2.0 to 3.5 & $4(7.8)$ & $1(14.3)$ & $0(0.0)$ & $3(7.5)$ \\
\hline Suction aspirator (operated by foot or electrically) & $20(39.2)$ & $5(71.4)$ & $2(50.0)$ & $13(32.5)$ \\
\hline Mucus trap for suction & $9(14.3)$ & $3(42.9)$ & $3(75.0)$ & $3(7.5)$ \\
\hline
\end{tabular}

From the interviews with health workers, they confirmed the shortage of equipment and added that some of the available equipment were worn out or outdated. The outdated equipment were mostly available in public health facilities.

"We are in a modernized world but surprisingly we are still using the old pumping BP machine that uses not less than 10 minutes to attend one patient instead of using monitor that takes one minute to measure BP, PR, Temperature, oxygen saturation. We need monitor so as to reduce waiting time for clients/patients when checking for vital signs". (labor ward nurse-1)

To explain the magnitude of the situation, in some facilities the main reported challenge was on neonatal resuscitation. The participants stated that on absence of resuscitation table it becomes very hard to ensure quality of care to the newborn.

"Newborn services we provide, I can say it is of quality. But there is what we call resuscitation table which we don't have it in labour ward as well as oxygen cylinder. So when we get a baby with difficulty breathing we are not in a position to help him/her breath instead we refer the baby" (Nurse-Midwife-3).

\section{Discussion}

Essential medicine and supplies is one of the six important health system building blocks as proposed by the WHO (11). Lack or challenges in meeting the demand of essential medicine and supplies have negative consequences in addressing any health challenge (12), maternal and new born health is no exception. Efforts to improve maternal health in the country has been receiving unequal gains. Lack or poor access and availability of essential medicine and supplies remain among the challenges in delivering quality emergency maternal and newborn care (EmONC) (13, 14). In realizing its needs, the revolutionary government of Zanzibar in collaboration with UNFPA conducted a baseline survey to examine key aspects and needs to deliver EmONC in 2012. One of the objectives was to examine availability of essential medicine for meeting EmONC targets in the isles. The evidence generated helped to guide the selected interventions and investment thereof. In looking on the remaining challenges, we conducted the current study to examine the current situation in terms of essential medicine and medical supplies.

In terms of essential medicine to prevent maternal and new-born deaths, evidence collected reveleal a persistent challenge in accessing some of the essential medicine. For maternal and newborn challenges, the leading causes of deaths include infections such as postpartum sepsis, haemorrhage both before, during, and after delivery, pregnancy induced hypertension and eclampsia, among others. Addressing such challenges call for ensuring availability of preventive and curative medicines at all the times in all facilities where delivery takes place.

For antibiotics, the commonest found essential item was amoxicillin while all others were at the level below $50 \%$. The challenge in availability is more common in lower level facilities compared to higher ones. This was the same for all other medicine. The challenge of poor availability of essential medicine in low level health facilities is common in other settings. Delivery of quality health services especially that of EmONC depends very much in availability of quality essential medicine (15). This can be improved when needs are established in time and medicines are ordered and delivered in time (16).

Apart from infections, other causes of maternal mortality include haemorrhage and pregnancy induced hypertension (16). This is also common trend in Tanzania (17). It is therefore essential to ensure availability of essential medicine to address these two conditions (18). To ensure quality EmONC service delivery, availability of antihypertensive and oxytocics is of paramount importance (15). In this survey, essential anti-colvusants were available in only two thirds of the facilities offering delivery services. Hypertensives were also not available in majority of health facilities. This is 
worrisome and could be one of the factors behind lives lost in health facilities in Zanzibar. Oxytocics are widely available and this is a significant improvement compared to the previous rates. Although some essential medicines are somehow not available in some surveyed facilities, interviewed health workers explained that the situation has improved significantly compared to the past.

Zanzibar has made significant improvement in ensuring availability essential medical supplies to address EmONC. Our observation and testimonies from the interviewed health workers revealed such improvement in supplies making up the delivery kit, resuscitation equipment, but not manual vacuum aspiration equipment. Such improvement needs to be sustained and extending to ensure replacement of wornout equipment to ensure delivery of quality health services (19).

\section{Study Limitation}

Some of the data used a cross sectional design that may limit studying causality. However, we employed mixed method design to ameliorate effects posed by designs. For example, the use of qualitative design helped to understand opinions from health workers and therefore somehow explain some of the results we presented. Despite covering all districts and regions in Zanzibar, data on EmONC presented in this report can lack generalizability to beyond health facilities. The use of qualitative survey which was not in the previous survey has captured voices of health workers in challenges they face in EmONC services as well as training and skills needed. Moreover, we used electronic data collection system that reduces chances of errors in data collection and cleaning. Quality of this data is therefore improved compared to the previous survey.

\section{Vi. Conclusion and Recommendations}

Availability of essential medicine and supplies for EmONC have improved in Zanzibar, but remains a challenge particularly in low level of health facilities. Efforts are needed to ensure availability of medicine and supplies to carter for all emergencies including anticonvulsants, antibiotics, and antihypertensives. Health facilities lack equipment for neonatal resuscitation.

\section{Abbreviations}

ANC: antenatal clinic;

AMDD: Averting Maternal Death and Disability;

EmONC: Emergency Obstetric and New-born Care; $\mathrm{MoH}$ : Ministry of Health;

ODK: open data kit;

PHCC: Primary Health Care Center;

PHCU: Primary Health Care Units;

PHCU+: Primary Health Care Units Plus;

SOPs: standard operating procedures;
UNFPA: United Nation Population Fund;

WHO: World Health Organization.

\section{Ethics approval and consent to participate}

The research team worked with the Ministry of Health Zanzibar on necessary documents for ethical approval by Zanzibar Institute Review Board. All ethical guidelines were followed to ensure ethical conduct with participants. Authorities were contacted for their approval; the $\mathrm{MoH}$ issued an introductory letter from the ministry to each relevant authority. Participation into this study was voluntary, and researchers ensured confidentiality and privacy of participants. Participants signed an informed consent before interviews and were free to stop the interview at any time without repercussion.

\section{Consent for publication}

Study participants were informed on the dissemination of the finds without disclosing their personal identity and they agreed.

Availability of data and materials

The dataset analyzed during the current study are available from the corresponding author on reasonable request.

\section{Competing interest}

The authors declare that they have no competing interest.

\section{Funding}

This study was funded by United Nation Population Fund.

\section{Authors' contribution}

ABP, BS, SM and SL designed the study. SM, BS, SM and GS supervised data collection. CM and LBM analysed the data. ABP and SM drafted the first manuscript. All authors reviewed the subsequent drafts of the manuscript and approved the final version for submission.

\section{ACKNOWLEDGEMENTS}

Thanks to UNFPA for the financial support. In particular, we would like to register our appreciation to Dr Azzah Amin Said Nofly, Ms. Batula Abdi, and Ms Salma Yussuf, for their tireless efforts in ensuring this survey is a success. We also acknowledge Ministry of Health for its immense support and advice. We are also indebted to Mr. Ali Hassan from Zanzibar $\mathrm{MoH}$ for dayto-day field and administrative support during the whole period of the study. It would have been impossible to realize this work without the profound support from Dr Ali Omar Ali, the programme manager of the Integrated Reproductive and Child Health Programme, under the Ministry of Health, Zanzibar. Of equal importance, we would also like to thank the research assistants and participants of this study for their immense support. 


\section{References Références Referencias}

1. WHO, UNICEF, UNFPA, Group WB, Nations U. Trends in maternal mortality: 1990 - 2015. 2015.

2. Fakih B, Nofly AAS, Ali A O, Mkopi A, Hassan A, Ali $A M$, et al. The status of maternal and newborn health care services in Zanzibar. BMC Pregnancy Childbirth. 2016; 16(1): 134.

3. Zalvand $\mathrm{R}$, Tajvar M, Pourreza A, Asheghi $\mathrm{H}$. Determinants and causes of maternal mortality in Iran based on ICD-MM: a systematic review. Reprod Health. 2019; 16(1):16.

4. Ameh C, Msuya S, Hofman J, Raven J, Mathai M, van den Broek N. Status of emergency obstetric care in six developing countries five years before the MDG targets for maternal and newborn health. PLoS One. 2012; 7(12): e49938.

5. MoHCDGEC Ministry of Health CD, Gender, Elderly and Children - MoHCDGEC/Tanzania Mainland, $\mathrm{MOH}$ Ministry of Health - MoH/Zanzibar, NBS National Bureau of Statistics - NBS/Tanzania, OCGS Office of Chief Government Statistician OCGS/Zanzibar, ICF. Tanzania Demographic and Health Survey and Malaria Indicator Survey 2015 2016. Dar es Salaam, Tanzania; 2016.

6. NBS. 2012 Population and Housing Census. Population Distribution by Administrative Areas. 2013. Available from: background: white"> http:// www.tzdpg.or.tz/fileadmin/documents/dpg_internal/ dpg_working_groups_clusters/cluster_2/water/WSD P/Background_information/2012_Census_General Report.pdf.

7. Alkema L, Chou D, Hogan D, Zhang S, Moller A B, Gemmill $A$, et al. Global, regional, and national levels and trends in maternal mortality between 1990 and 2015, with scenario-based projections to 2030: a systematic analysis by the UN Maternal Mortality Estimation Inter-Agency Group. Lancet. 2016; 387(10017): 462-74.

8. Pembe A B, Sunguya B F, Leshabari S, Mushi S, Masaki C, Kiwango K, et al. Progress Made in Addressing Emergency Obstetric and Newborn Care Challenges in Zanzibar2019; 19(1). Available from: https://globaljournals.org/GJMR_Volume19/1Progress-Made-in-Addressing.pdf.

9. Disability. AAMDa. Needs Assessment of Emergency Obstetric and Newborn Care: Data Collection Modules.

10. Organization. WH, UNFPA., UNICEF., Disability. AMD. Monitoring emergency obstetric care, a handbook.2009.

11. WHO., Everybody's business: strengthening health systems to improve health outcomes: WHO's framework for action.2007.

12. Roth L, Bempong D, Babigumira J B, Banoo S, Cooke E, Jeffreys D, et al. Expanding global access to essential medicines: investment priorities for sustainably strengthening medical product regulatory systems. Global Health. 2018; 14(1): 102.

13. Sumankuuro J, Crockett J, Wang S. Perceived barriers to maternal and newborn health services delivery: a qualitative study of health workers and community members in low and middle-income settings. BMJ Open. 2018; 8(11): e021223.

14. Winter R, Yourkavitch J, Wang W, Mallick L. Assessment of health facility capacity to provide newborn care in Bangladesh, Haiti, Malawi, Senegal, and Tanzania. J Glob Health. 2017; 7(2): 020509.

15. Anyakora C, Oni Y, Ezedinachi U, Adekoya A, Ali I, Nwachukwu C, et al. Quality medicines in maternal health: results of oxytocin, misoprostol, magnesium sulfate and calcium gluconate quality audits. BMC Pregnancy Childbirth. 2018; 18(1): 44.

16. Spisak C, Morgan L, Eichler R, Rosen J, Serumaga B, Wang A. Results-Based Financing in Mozambique's Central Medical Store: A Review After 1 Year. Glob Health Sci Pract. 2016; 4(1): 165-77.

17. Manyeh A K, Nathan R, Nelson G. Maternal mortality in Ifakara Health and Demographic Surveillance System: Spatial patterns, trends and risk factors, 2006 - 2010. PLoS One. 2018; 13(10): e0205370.

18. Paxton A, Maine D, Freedman L, Fry D, Lobis S. The evidence for emergency obstetric care. Int $J$ Gynaecol Obstet. 2005; 88(2): 181-93.

19. WHO. Interagency list of medical devices for essential intervention for Reproductive, Maternal, Newborn and Child Health. Switzerland: World Health Organization; 2015. 